\title{
Interfacial Fracture Toughness Evaluation of Poly(L-lactide acid)/Natural Fiber Composite by Using Double Shear Test Method
}

\author{
Chin Voon Sia ${ }^{1,2}$, Yoshikazu Nakai', Hiroshi Tanaka1, Daiki Shiozawa1 \\ ${ }^{1}$ Department of Mechanical Engineering, Kobe University, Kobe, Japan \\ ${ }^{2}$ School of Engineering, Computing and Science, Swinburne University of Technology Sarawak Campus, \\ Kuching, Sarawak, Malaysia \\ Email: ${ }^{*}$ cvsia@swinburne.edu.my
}

Received 18 February 2014; revised 18 March 2014; accepted 25 March 2014

Copyright (C) 2014 by authors and Scientific Research Publishing Inc.

This work is licensed under the Creative Commons Attribution International License (CC BY). http://creativecommons.org/licenses/by/4.0/

(c) (i) Open Access

\section{Abstract}

In this work, interfacial fracture toughness between treated fiber and matrix was investigated by using double shear test method. Susrface treatment on the oil palm empty fruit bunch (OPEFB) fibers was performed to improve the interfacial bosnding properties of natural fiber reinforced Poly(L-lactide acid) composites. Three fibers model composite and four fibers model composite were prepared for the double shear test. The interfacial fracture toughness of both model composites is dependent on matrix length. In addition, the interfacial fracture toughness and the critical interfacial shear stress were increased with increasing the concentration of $\mathrm{NaOH}$ and the duration of surface treatment.

\section{Keywords}

Fiber, Interfacial Fracture Toughness, Interfacial Shear Strength, Surface Treatment

\section{Introduction}

Fiber reinforced plastic (FRP) composites have played an important role in various applications for their high specific strength and modulus. Recently, renewal of interest in the research of fibers derived from natural sustainable sources as potential reinforcement for high performance composites has been growing. The increasing

${ }^{*}$ Corresponding author.

How to cite this paper: Sia, C.V., et al. (2014) Interfacial Fracture Toughness Evaluation of Poly(L-lactide acid)/Natural Fiber Composite by Using Double Shear Test Method. Open Journal of Composite Materials, 4, 97-105.

http://dx.doi.org/10.4236/ojcm.2014.42011 
interest in the biodegradable composites reinforced with natural fibers [1]-[5] due to the advantages of being biodegradable, renewable, environmentally friendly and low cost. However, many studies revealed that the poor mechanical properties of natural fibers reinforced composites can be attributed to the low interfacial bonding strength between fiber and matrix [6]-[8]. Therefore, there is an interest in developing test methods for measuring the interfacial toughness between fiber and matrix.

The recent evaluation crack propagation behaviour of FRP was based on meso-mechanical analysis. The common test methods used to evaluate the interfacial fracture between fiber and matrix are Microbond test [9]-[11], Broutman test [12], fiber push-out [13] and fiber pull-out test [14]. The crack propagation in FRP was evaluated from fracture process like matrix fracture and fiber/matrix interfacial cracking [15]-[17]. Kotaki et al. [18] and Hojo et al. [19] reported that the crack propagation behavior in FRP is strongly influenced by the interfacial bonding between fiber and matrix. Koiwa et al. [20] introduced the measurement on the interfacial fracture toughness of Mode I and Mode II crack growth by using real size model composite. They reported a significant increase in fracture toughness with increasing bonding length. However, the results of fracture toughness were evaluated at a very short range of the matrix lengths.

In the present study, Mode II interfacial fracture toughness between treated oil palm empty fruit bunch (OPEFB) fiber and Poly(L-lactide acid) (PLLA) composite was evaluated by using the double shear test method which consists of 3 fibers model composite and 4 fibers model composite. The fibers used in both model composites were pretreated $0.5 \mathrm{M}$ alkali solution for $24 \mathrm{~h}$. In addition, $0.5 \mathrm{M}, 2 \mathrm{~h}$ alkali treated fibers were also prepared in the present study in order to compare the effects of the alkali treatments on interfacial fracture toughness and the critical interfacial shear stress of the model composites. Scanning electron microscope (SEM) was utilized to observe the morphology of the crack propagation between fiber/matrix interfaces.

\section{Experimental}

\subsection{Materials}

OPEFB fibers were purchased from Ecofibre Technology Sdn. Bhd, Malaysia. These untreated fibers were approximately 150 - $550 \mu \mathrm{m}$ diameter and 40 - $150 \mathrm{~mm}$ in length. PLLA fibers with diameter of $0.2 \mathrm{~mm}$ were supplied by Unitika Ltd, Japan and sodium hydroxide $(\mathrm{NaOH})$ was purchased in Hyogo, Japan.

\subsection{Surface Treatment}

OPEFB fibers were kept in oven at $21^{\circ} \mathrm{C} \pm 1^{\circ} \mathrm{C}$ for $24 \mathrm{~h}$ for conditioning which according to ASTM D1776-04 [21]. The fibers were then separately soaked in $0.5 \mathrm{M} \mathrm{NaOH}$ solution for 2 hand $1.0 \mathrm{M} \mathrm{NaOH}$ solution for $24 \mathrm{~h}$. After completing treatment, the alkali treated fibers were washed and rinsed with distilled water for several times until the final $\mathrm{pH}$ was maintained at 7.0. Finally, the fibers were dried at room temperature for $48 \mathrm{~h}$ before making the composites.

\subsection{Model Composite Specimens}

Three fiber model composite and four fibers model composite were prepared for the Mode II interfacial test. Prior to preparing the specimens, OPEFB fibers were aligned closely in parallel on a paper tab with a small tension force applied on the fibers to avoid loosening of the fibers. Both end points of the fibers were then glued by using epoxy resin adhesive. After the fibers were aligned, a small amount of melted PLLA obtained from a PLLA fiber was placed at the mid-point in between 2 OPEFB fibers. The final matrix length of the specimen was measured after the melted PLLA was completely cured. The schematics and SEM micrographs of the 3 fibers model specimen and 4 fibers model specimen were shown in Figure 1 and Figure 2 respectively. The matrix length, $L$ of the test specimens was from 0.24 to $5.81 \mathrm{~mm}$, and the angle of the fibers, $2 \theta$ which shown in Figure 1(a) and Figure 1(b) for bonding section was from 98 to 180 degrees.

\subsection{Mode II Interfacial Test Method}

Double shear test of the specimens were carried out by using a Tohei MT201 tensile test machine with a crosshead speed of $9 \mathrm{~mm} / \mathrm{min}$ and $50 \mathrm{~N}$ loads.

Figure 3(a) and Figure 3(b) show the schematics of the three fibers double shear model composite and the 


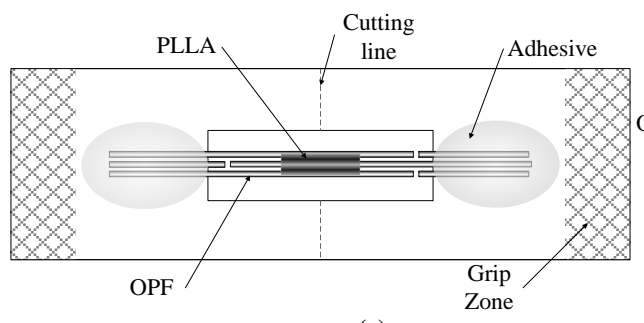

(a)

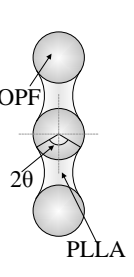

PLLA

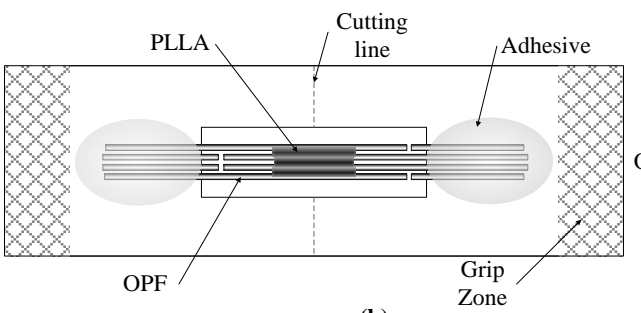

(b)

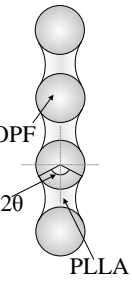

PLla

Figure 1. Schematics of the model composites. (a) 3 fibers model composite (b) 4 fibers model composite.

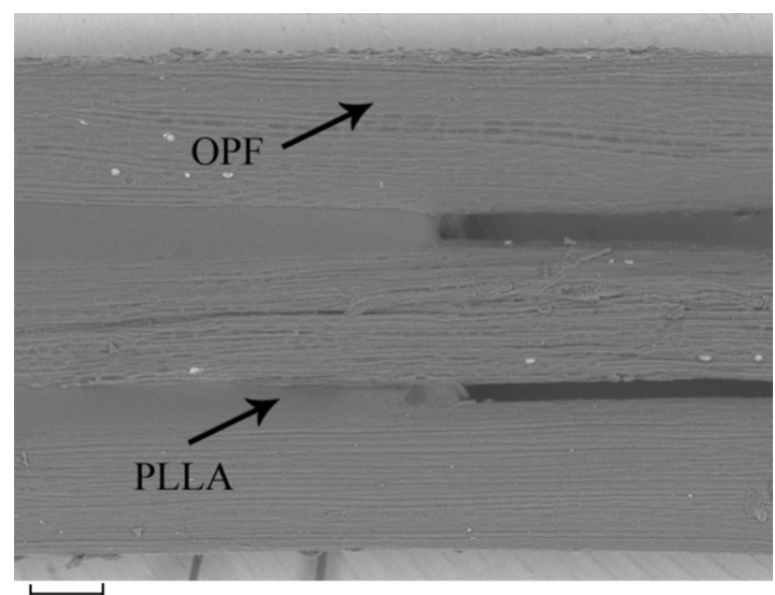

$\stackrel{\longmapsto}{100 \mu \mathrm{m}}$ (a)

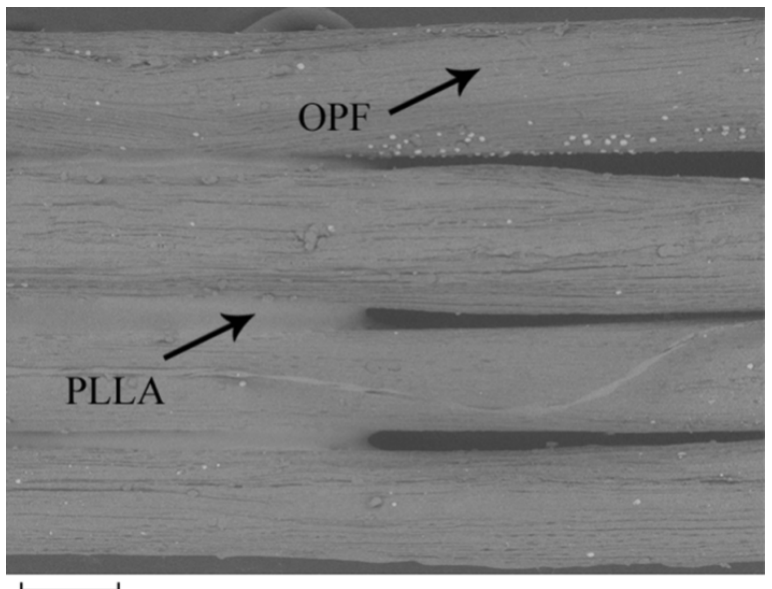

(b)

Figure 2. SEM Micrographs of the model composites. (a) 3 fibers model composite. (b) 4 fibers model composite.

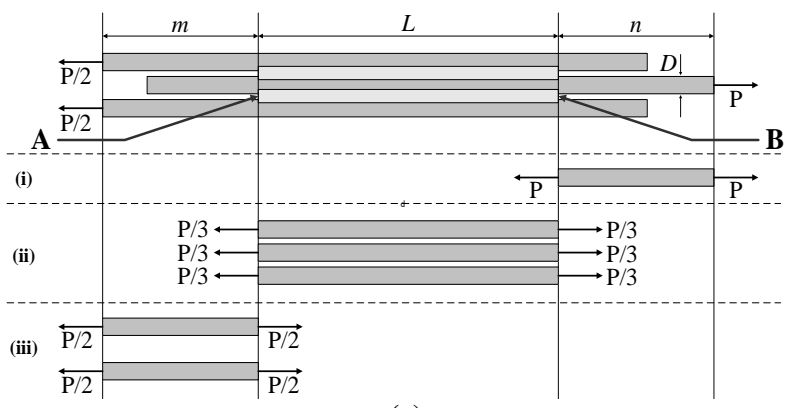

(a)

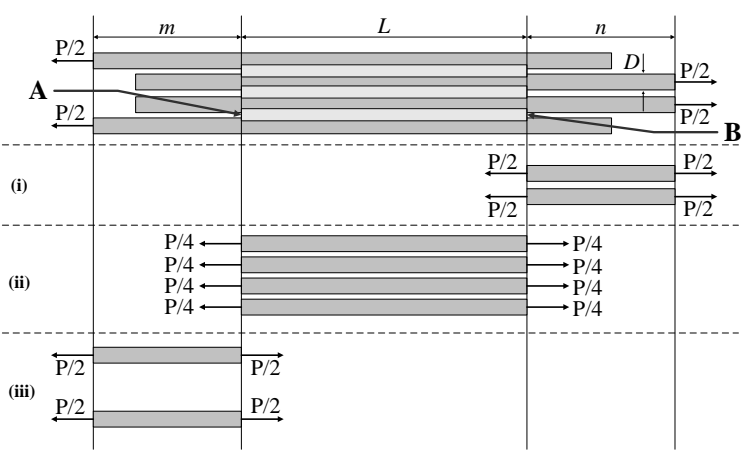

(b)

Figure 3. Schematics of double shear model composites. (a) 3 fibers model composite. (b) 4 fibers model composite.

four fibers double shear model composite respectively. By simplifying the model composites into Sections 1-3, the strain energy of the model composites can be obtained as below.

$$
U=U_{\mathrm{i}}+U_{\mathrm{ii}}+U_{\mathrm{iii}}
$$

where $U_{\mathrm{i}}, U_{\mathrm{ii}}$ and $U_{\mathrm{iii}}$ are the strain energy of the Section (1), (2) and (3) in Figure 3(a) and Figure 3(b). The equations of $U_{\mathrm{i}}, U_{\mathrm{ii}}$ and $U_{\mathrm{iii}}$ are stated below.

Three fibers model:

$$
U_{\mathrm{i}}=\frac{2 P^{2} n}{\pi E D^{2}} ; \quad U_{\mathrm{ii}}=\frac{2 P^{2} L}{3 \pi E D^{2}} ; \quad U_{\mathrm{iii}}=\frac{P^{2} m}{\pi E D^{2}}
$$

Four fibers model: 


$$
U_{\mathrm{i}}=\frac{P^{2} n}{\pi E D^{2}} ; \quad U_{\mathrm{ii}}=\frac{P^{2} L}{2 \pi E D^{2}} ; \quad U_{\mathrm{iii}}=\frac{P^{2} m}{\pi E D^{2}}
$$

where $E=4.95 \mathrm{GPa}$ [22], $D$ is diameter of OPEFB fiber, $P$ is the applied force, $L, m$ and $n$ are the length of the section in Figure 3(a) and Figure 3(b).

The energy release rate at crack tip A and B are given by the following equations.

Three fibers model:

$$
\begin{aligned}
& G_{\mathrm{A}}=\frac{1}{2 \theta D} \cdot \frac{\mathrm{d}}{\mathrm{d} m}\left(U_{\mathrm{i}}+U_{\mathrm{ii}}+U_{\mathrm{iii}}\right)=\frac{1}{2 \theta D}\left(\frac{\mathrm{d} U_{\mathrm{iii}}}{\mathrm{d} m}-\frac{\mathrm{d} U_{\mathrm{ii}}}{\mathrm{d} L}\right)=\frac{P^{2}}{6 \pi E D^{3} \theta} \\
& G_{\mathrm{B}}=\frac{1}{2 \theta D} \cdot \frac{\mathrm{d}}{\mathrm{d} n}\left(U_{\mathrm{i}}+U_{\mathrm{ii}}+U_{\mathrm{iii}}\right)=\frac{1}{2 \theta D}\left(\frac{\mathrm{d} U_{\mathrm{i}}}{\mathrm{d} n}-\frac{\mathrm{d} U_{\mathrm{ii}}}{\mathrm{d} L}\right)=\frac{2 P^{2}}{3 \pi E D^{3} \theta}
\end{aligned}
$$

Four fibers model:

$$
\begin{aligned}
& G_{\mathrm{A}}=\frac{1}{2 \theta D} \cdot \frac{\mathrm{d}}{\mathrm{d} m}\left(U_{\mathrm{i}}+U_{\mathrm{ii}}+U_{\mathrm{iii}}\right)=\frac{1}{2 \theta D}\left(\frac{\mathrm{d} U_{\mathrm{iii}}}{\mathrm{d} m}-\frac{\mathrm{d} U_{\mathrm{ii}}}{\mathrm{d} L}\right)=\frac{P^{2}}{4 \pi E D^{3} \theta} \\
& G_{\mathrm{B}}=\frac{1}{2 \theta D} \cdot \frac{\mathrm{d}}{\mathrm{d} n}\left(U_{\mathrm{i}}+U_{\mathrm{ii}}+U_{\mathrm{iii}}\right)=\frac{1}{2 \theta D}\left(\frac{\mathrm{d} U_{\mathrm{i}}}{\mathrm{d} n}-\frac{\mathrm{d} U_{\mathrm{ii}}}{\mathrm{d} L}\right)=\frac{P^{2}}{4 \pi E D^{3} \theta}
\end{aligned}
$$

Since the matrix length is measured after the resin is cured, the both sides of the center fiber may have different matrix lengths. By considering one outer fiber bonded with minimum matrix length, $L_{\min }$ in Section (3) from the Figure 3(a) or Figure 3(b) have the equilibrium of forces in longitudinal direction, the mean interfacial shear stress at the shortest interface of fiber/matrix with bonding area, $A=D \theta L_{\min }$ can be defined as:

$$
\tau_{\mathrm{i}}=\frac{P}{2 D \theta L_{\min }}
$$

\subsection{Scanning Electron Microscopy (SEM)}

Treated and untreated fiber surface were observed by using a (Hitachi, TM3000, Japan) scanning electronmicroscope. The SEM fractography of the model composites were also investigated and the bonding angle, $2 \theta$ can be obtained from the SEM images by using image analyzing software (ImageJ v1.38x, National Institutes of Health, Bethesda, USA).

\section{Result and Discussion}

\subsection{Surface Characterization of Treated Fibers}

Alkali treatment of OPEFB fibers causes disruption of hydrogen bonding in the network structure. This treatment also removes certain amount of lignin, wax, oils and other impurities that cover on the external surface layer of the fiber. As a result, the surface roughness of the fiber is improved [7] [23]-[25]. Figure 4(a) and Figure 4(b) and Figure 4(c) show the SEM micrographs of the untreated fiber, fiber treated with $0.5 \mathrm{M} \mathrm{NaOH}$ for $2 \mathrm{~h}$ and fiber treated with 1.0 M NaOH for $24 \mathrm{~h}$ respectively. As seen in Figure 4(b) and Figure 4(c), the roughness of fiber surface increased when the concentration of alkali solution and the duration of alkali treatment were increased.

\subsection{Interfacial Fracture Toughness of the Model Composites}

For all cases, the interfacial fracture toughness, $G_{\mathrm{i}}$ was found independent on the fiber diameters, $D$, angle of bonding interface, $2 \theta$ and spacing between fibers, $t$. However, interfacial fracture toughness of both model composites does depend on the matrix length (Figure 5). For $0.24<L<2.35 \mathrm{~mm}$, the $G_{\mathrm{i}}$ value of the 3 fibers model composite increases from $14.7 \mathrm{~J} / \mathrm{m}^{2}$ to $108.6 \mathrm{~J} / \mathrm{m}^{2}$ as the $L$ increased. The $G_{\mathrm{i}}$ value is stable at $L>2.35$ $\mathrm{mm}$. Hence, the data points $\mathrm{s}$ to the matrix lengths ranging more than $2.35 \mathrm{~mm}$ were used to calculate the average $G_{\mathrm{i}}$ value $\left(70.8 \pm 13.7 \mathrm{~J} / \mathrm{m}^{2}\right)$. Same observation was found in 4 fibers model composite. For $0.66<L<2.29$ $\mathrm{mm}, G_{\mathrm{i}}$ value of the 4 fibers model composite increases from $21.4 \mathrm{~J} / \mathrm{m}^{2}$ to $102.4 \mathrm{~J} / \mathrm{m}^{2}$ as the $L$ in- 


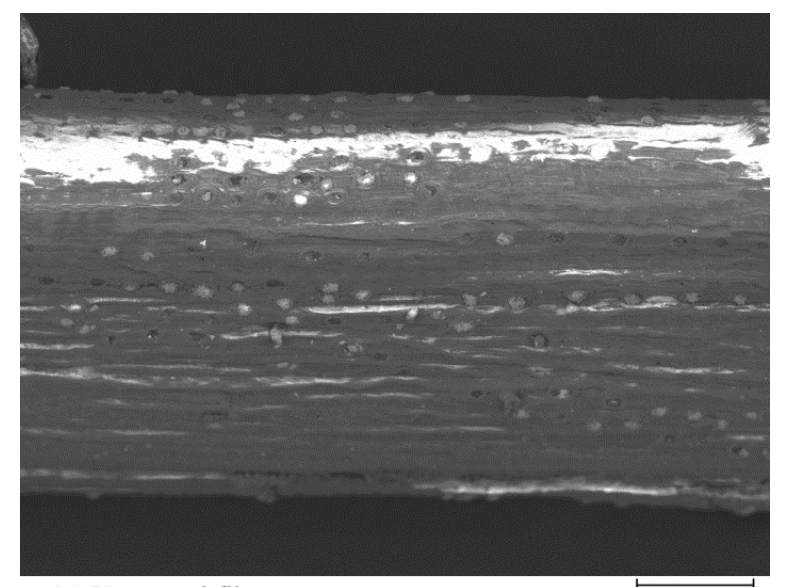

(a) Untreated fiber

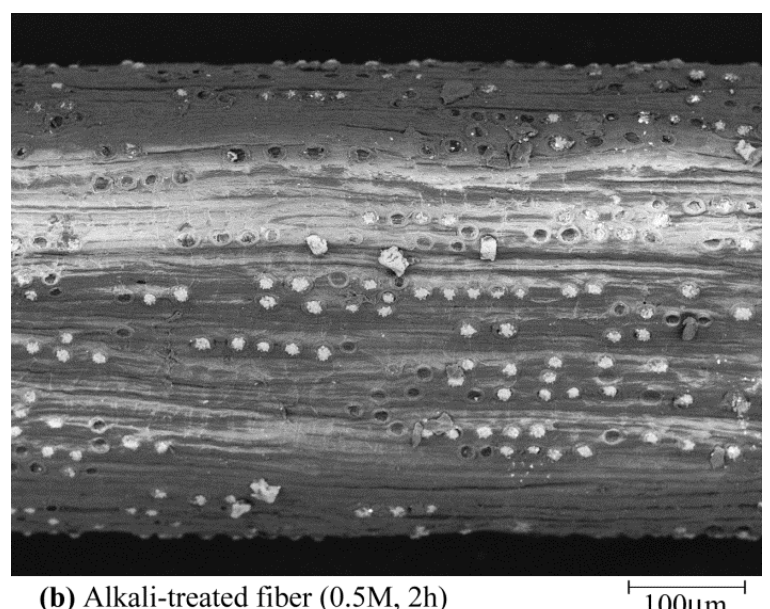

(b) Alkali-treated fiber (0.5M, 2h)

$100 \mu \mathrm{m}$

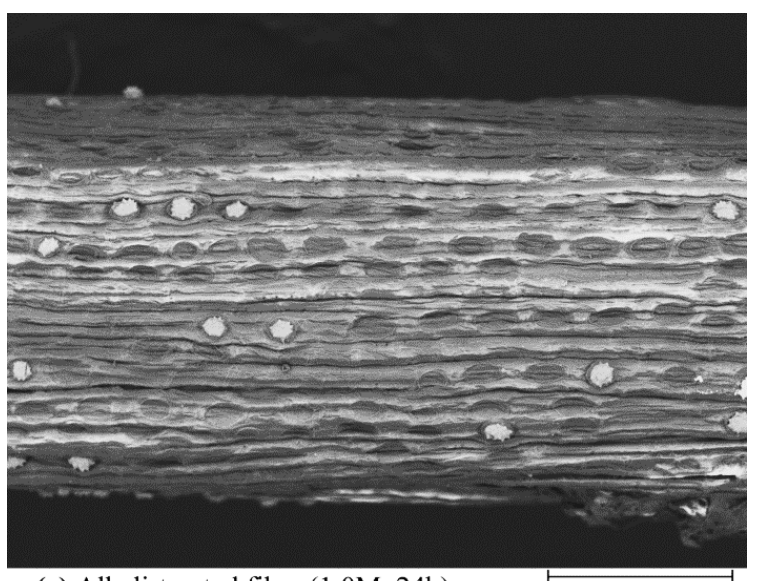

(c) Alkali-treated fiber (1.0M, 24h)

$100 \mu \mathrm{m}$

Figure 4. Scanning electron micrographs of OPEFB fiber surface. (a) Untreated fiber, (b) Treated fiber (2 h, $0.5 \mathrm{M}$ $\mathrm{NaOH})$ (c) Treated fiber (24 h, 1.0 M NaOH).

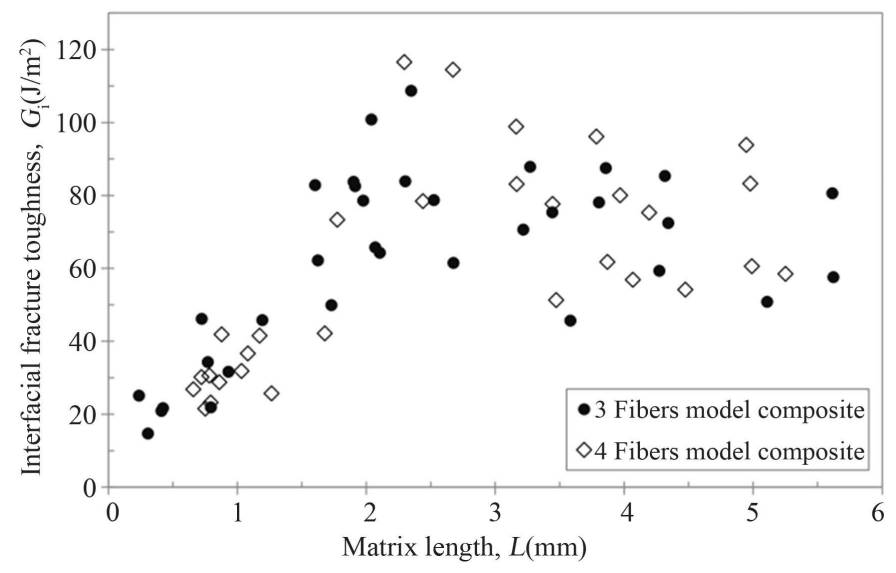

Figure 5. Interfacial fracture toughness of the 3 fibers model composite and the 4 fibers model composite at various matrix lengths.

creased. After that, the $G_{\mathrm{i}}$ value is stable with further increase in matrix length. For $L>3 \mathrm{~mm}$, the average $G_{\mathrm{i}}$ value obtained from the data points is $73.6 \pm 15.7 \mathrm{~J} / \mathrm{m}^{2}$. A slight difference from the average $G_{\mathrm{i}}$ value of the 3 fibers model composite was observed.

The increase of interfacial fracture toughness, $G_{\mathrm{i}}$ with matrix length, $L$ at small matrix lengths was attributed 
to the increase in volume of matrix for plastic deformation in response to shear. However, the interfacial fracture toughness leveling off when the plastic deformation at the crack tip no longer occupies uniformly the entire matrix length, but constraint at the vicinity at the crack tips with further increase in matrix length, $L$ [26]-[28].

Figure 6 shows the relationship between interfacial fracture toughness and matrix length with different fiber treatment conditions. As seen in Figure 6, the $G_{\mathrm{i}}$ value of the 3 fibers model composite with $0.5 \mathrm{M}, 2 \mathrm{~h}$ alkali treated fibers generally increased with matrix length until a stable value was reach at matrix length about 2.5 $\mathrm{mm}$. The average $G_{\mathrm{i}}$ value obtained from the data points at $L>2.5 \mathrm{~mm}$ is $57.1 \pm 10.4 \mathrm{~J} / \mathrm{m}^{2}$, which is $13.7 \mathrm{~J} / \mathrm{m}^{2}$ lower than the average $G_{\mathrm{i}}$ value of the 3 fibers model composite with $1.0 \mathrm{M}, 24 \mathrm{~h}$ alkali treated fibers.

\subsection{Interfacial Shear Stress}

Figure 7 and Figure 8 present the relationship between mean interfacial shear stress, $\tau_{\mathrm{i}}$ and bonding area at minimum bonding length, $A$. As illustrated in Figure 7 and Figure 8, the mean interfacial shear stress, $\tau_{\mathrm{i}}$ of the model composite decreased with increasing in bonding area, $A$. Similar observations were found in other studies for kevlar fiber [9], glass fiber [29], carbon fiber [30], and steel wire [31] which bonded with either thermoplastic orthermosetting adhesives. The $\tau_{\mathrm{i}}-A$ relation can be explained as follows. The occurrence probability of the critical flaws increases with increasing the bonding area, thereby increasing the chances that initiate fracture upon loading [29]-[31].

As seen in Figure 7, the $\tau_{\mathrm{i}}$ values of the 3 fibers model composite have some slight differences with the $\tau_{\mathrm{i}}$ values of the 4 fibers model composite, but in general results are in rather good agreement with the results ob-

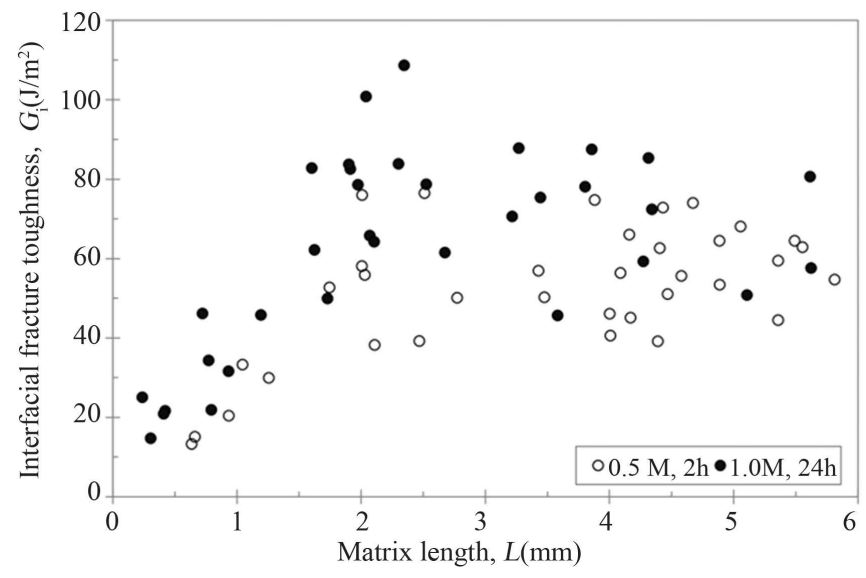

Figure 6. Interfacial fracture toughness of the 3 fibers model composite with different fiber treatment conditions.

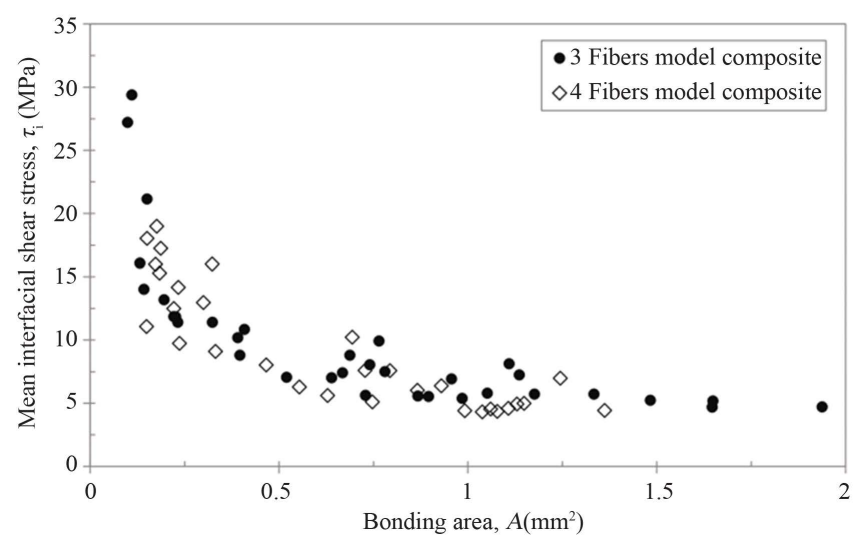

Figure 7. Mean interfacial shear stress versus minimum matrix length of the 3 fibers model composite and the 4 fibers model composite. 
tained from 4 fibers model composite. Figure 8 compares the $\tau_{\mathrm{i}}$ - $A$ relation of the model composites with different alkali treatment conditions. The overall $\tau_{\mathrm{i}}$ value of the model composite with $0.5 \mathrm{M}, 2 \mathrm{~h}$ alkali treated fibers are slightly lower than the $\tau_{\mathrm{i}}$ value of the model composite with $1.0 \mathrm{M}, 24$ halkali treated fibers. As explanation above, the improvement of the mean interfacial shear stress is believed to be due to surface roughening by the alkali treatment. This promotes better interlocking between fiber and matrix and improves the interfacial adhesion.

\subsection{Morphological Analysis}

Figure 9 and Figure 10 show the micrographs of the fracture surface at the initial crack tips of the treated fiber/ PLLA models. The surface of the fiber can be clearly observed from Figure 9(a) and the matrix was also found on the surface of the outer fiber (Figure 9(b)). Therefore, the crack was propagated along the interface between center fiber and matrix. From the experimental data, 31 out of 34 tested 3 fibers model composites and 18 out of 30 tested 4 fibers model composites were identified where the crack was propagated along the interface between

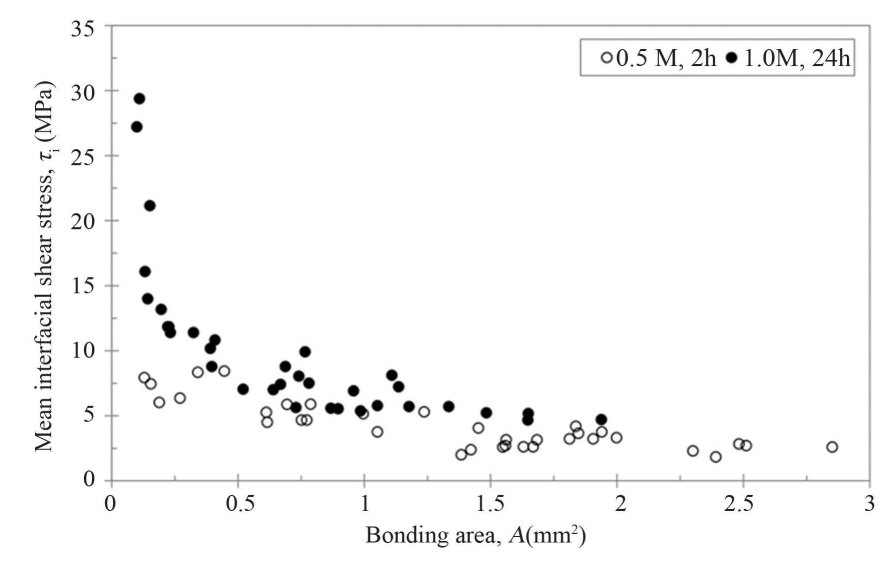

Figure 8. Mean interfacial shear stress versus minimum matrix length of the 3 fibers model composite with different fiber treatment conditions.

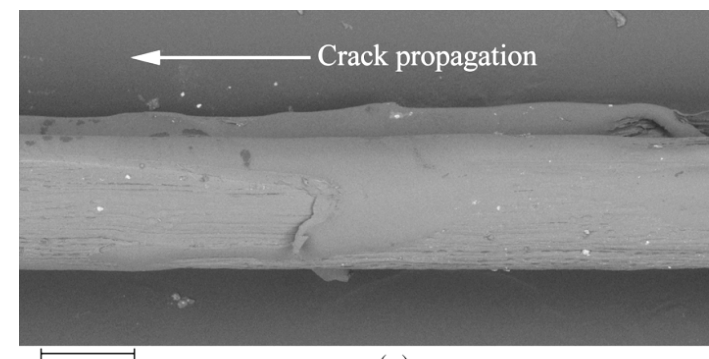

$200 \mu \mathrm{m}$ (a)

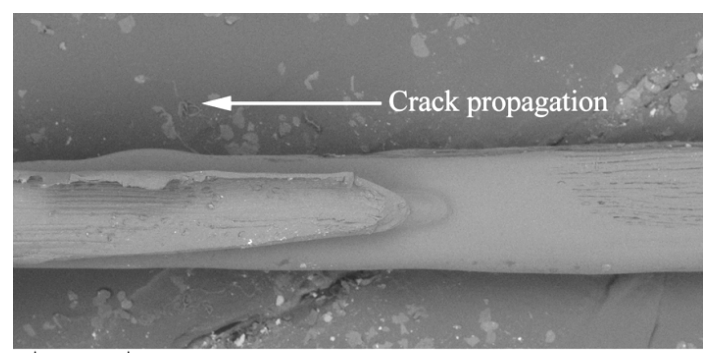

$200 \mu \mathrm{m}$ (b)

Figure 9. Fracture surface of the specimen (center fiber/matrix interface). (a) Center fiber. (b) Outer fiber.

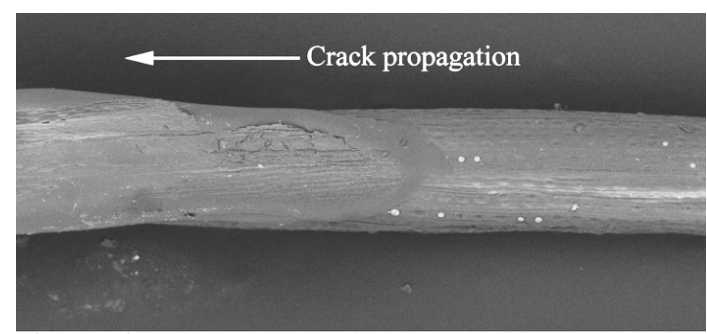

$200 \mu \mathrm{m}$

(a)

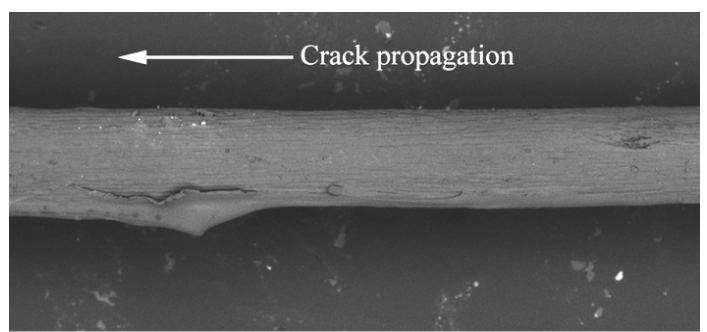

$\stackrel{\longmapsto}{200 \mu \mathrm{m}}$ (b)

Figure 10. Fracture surface of the specimen (outer fiber/matrix interface). (a) Center fiber. (b) Outer fiber. 
center fiber and matrix.

\section{Conclusions}

The present work evaluated the interfacial fracture toughness and the interfacial shear stress of the treated OPEFB fiber/PLLA model composites. The following conclusions can be drawn from this work:

1) The interfacial fracture toughness of the model composites is dependent on matrix length. The average interfacial fracture toughness can be successfully evaluated at $L>2.35 \mathrm{~mm}$ for 3 fibers model composite and at $L>$ $3 \mathrm{~mm}$ for 4 fibers model composite.

2) The mean interfacial shear stress decreases with increasing in bonding area, $A$. This may be due to the increase of the occurrences probability of the critical defects when the bonding interface between fiber and matrix was increased.

3) The interfacial fracture toughness and the mean interfacial shear stress of the model composite increase with increasing the concentration of alkali solution and the duration of surface treatment.

\section{References}

[1] Mohanty, A.K., Misra, M. and Drzal, L.T. (2005) Natural Fibers, Biopolymers and Biocomposite. CRC Press, Boca Raton. http://dx.doi.org/10.1201/9780203508206

[2] Shinoj, S., Visvanathan, R., Panigrahi, S. and Kochubabu, M. (2011) Oil Palm Fiber (OPF) and Its Composite: A Review. Industrial Crops and Products, 33, 7-22. http://dx.doi.org/10.1016/j.indcrop.2010.09.009

[3] Roy, A., Chakraborty, S., Kundu, S.P., Basak, R.K., Majumder, S.B. and Adhikari, B (2012) Improvement in Mechanical Properties of Jute Fibers through Mild Alkali Treatment as Demonstrated by Utilization of the Weibull Distribution Model. Bioresource Technology, 107, 222-228. http://dx.doi.org/10.1016/j.biortech.2011.11.073

[4] Gassan, J. and Bledzki, A.K. (1999) Alkali Treatment of Jute Fibres: Relationship between Structure and Mechanical Properties. Journal of Applied Polymer Science, 71, 623-629. http://dx.doi.org/10.1002/(SICI)1097-4628(19990124)71:4<623::AID-APP14>3.0.CO;2-K

[5] Gu, H. (2009) Tensile Behaviours of the Coir Fibre and Related Composites after NaOH Treatment. Materials and Design, 30, 3931-3934. http://dx.doi.org/10.1016/j.matdes.2009.01.035

[6] Islam, M.S., Pickering, K.L. and Foreman, N.J. (2010) Influence of Alkali Treatment on the Interfacial and PhysicoMechanical Properties of Industrial Hemp Fibre Reinforced Polylatic Acid Composites. Composites: Part A, 41, 596-603. http://dx.doi.org/10.1016/j.compositesa.2010.01.006

[7] Moshiul Alam, A.K.M., Beg, M.D.H, Reddy Rasad, D.M., Khan, M.R. and Mona, M.F. (2012) Structures and Performances of Simultaneous Ultrasound and Alkali Treated Oil Palm Empty Fruit Bunch Fiber Reinforced Poly(lactic acid) Composites. Composites: Part A, 41, 1921-1929. http://dx.doi.org/10.1016/j.compositesa.2012.06.012

[8] Song, Y.S., Lee, J.T., Sun, J.D. Kim, M.W., Lee, S.H. and Youn, J.R. (2012) Viscoelastic and Thermal Behavior of Woven Hemp Fiber Reinforced Poly(lactic acid) Composites. Composites: Part B, 43, 856-860. http://dx.doi.org/10.1016/j.compositesb.2011.10.021

[9] Day, R.J. and Cauich Rodrigez, J.V. (1998) Investigation of the Micromechanics of the Microbond Test. Composites Science and Technology, 58, 907-914. http://dx.doi.org/10.1016/S0266-3538(97)00197-8

[10] Chou, C.T., Gaur, U. and Miller, B. (1994) The Effect of Microvise Gap Width on Microbond Pull-Out Test. Composites Science and Technology, 51, 111-116. http://dx.doi.org/10.1016/0266-3538(94)90161-9

[11] Zinck, P, Wagner, H.D., Salmon, L. and Gerard, J.F. (2001) Are Microcomposites Realistic Models of the Fibre/Matrix Interface? I. Micromechanical Modelling. Polymer, 42, 5401-5413. http://dx.doi.org/10.1016/S0032-3861(00)00870-3

[12] Broutman, L.J. (1969) Measurement of the Fiber-Polymer Matrix Interfacial Strength. Interfaces in Composites, ASTM STP 452, 27-41.

[13] Schlapschi, K.H., Meier, B. and Grathwohl, G. (1994) Evaluation of Interface Parameters in Push-Out and Pull-Out Tests. Composites, 25, 476-481. http://dx.doi.org/10.1016/0010-4361(94)90172-4

[14] So, C.L. and Young, R.J. (2001) Interfacial Failure in Poly(p-phenylenebenzobisoxazole) (PBO)/Epoxy Single Fibre Pull-Out Specimens. Composites: Part A, 32, 445-455. http://dx.doi.org/10.1016/S1359-835X(00)00106-8

[15] Crews, J.H., Shivakumar, K.N. and Raju, I.S. (1992) A Fibre-Resin Micromechanics Analysis of the Delamination Front in a Double Cantilever Beam Specimen. Phase Interaction in Composite Materials, 396-405.

[16] Dubois, F. and Keunings, R. (1997) DCB Testing of Thermoplastic Composites: A Non-Linear Micro-Macro Numerical Analysis. Composites Science and Technology, 57, 437-450. http://dx.doi.org/10.1016/S0266-3538(96)00166-2 
[17] Tanaka, H. and Nakai, Y. (2004) Three-Dimensional Micromechanics Analysis of Strain Energy Release Rate Distribution along Delamination Crack in FRP. Proceeding of 4th Asian-Australasian Conference on Composite Materials, Sydney, 6-9 July 2004, 439-444.

[18] Kotaki, M., Hojo, M., Tsujioka, N. and Hamada, H. (1995) Effect of Surface Treatment on Interlaminar/Intralaminar Crack Growth Behavior of CFRP Laminates. Proceeding of 4th Japan International SAMPE Symposium, Tokyo, 25-28 September 1995, 1008-1013.

[19] Hojo, M., Tsujioka, N., Kotaki, M., Hamada, H., Maekawa, Z. and Ochiai, S. (1995) Effect of Interfacial Strength on Interlaminar and Intralaminar Fracture Toughness of CFRP Laminates. Proceeding of 5th International Symposium on High Technology Composites in Modern Application, Corfu, 18-22 September 1995, 30-36.

[20] Koiwa, K., Tanaka, H., Nakai, N., Ito, S. and Tukahara, T. (2011) Fracture Mechanics Evaluation of Mode I and Mode II Fiber/Matrix Interfacial Crack by Using Real-Size Model Composite. Proceeding of International Conference on Advanced Technology in Experimental Mechanics, Kobe, 19-21 September 2011.

[21] ASTM (2004) ASTM D1776-04. Standard Practice for Conditioning and Testing Textiles. American Society for Testing and Materials, Pennsylvania.

[22] Sia, C., Nakai, Y. and Shiozawa, D. (2013) Influence of Alkali Treatment on the Mechanical Properties of Oil Palm Fibers. Proceeding of 4th Japan Conference on Composite Materials, Japan, 7-9 March 2013.

[23] Li, X., Tabil, L.G. and Panigrahi, S. (2007) Chemical Treatment of Natural Fiber for Use in Natural Fiber-Reinforced Composites: A Review. Journal of Polymers and the Environment, 15, 25-33. http://dx.doi.org/10.1007/s10924-006-0042-3

[24] Sreekala, M.S., Kumaran, M.G., Joseph, R. and Thomas, S. (2001) Stress-Relaxation Behaviour in Composites Based on Short Oil-Palm Fibres and Phenol Formaldehyde Resin. Composites Science and Technology, 61, 1175-1188. http://dx.doi.org/10.1016/S0266-3538(00)00214-1

[25] Yousif, B.F. and Tayeb, E.N.S.M. (2007) The Effect of Oil Palm Fibers as Reinforcement on Tribological Performance of Polyester Composites. Surface Review and Letter, 14, 1095-1102. http://dx.doi.org/10.1142/S0218625X07010561

[26] Chai, H. (1988) Shear Fracture. International Journal of Fracture, 37, 137-159.

[27] Daghyani, H.R., Ye, L. and Mai, Y.W. (1995) Constraint Effect on Fracture Behaviour of Adhesive Joints with Different Bond Thickness. Fracture Mechanics. ASTM Special Technical Publication, 1256, 556-571.

[28] Cheng, Y., Mai, Y.W. and Lin, Y. (2001) Effect of Bond Thickness on Fracture Behaviour in Adhesive Joints. Journal of Adhesive, 75, 27-44. http://dx.doi.org/10.1080/00218460108029592

[29] Zhandarov, S. and Mader, E. (2005) Characterization of Fiber/Matrix Interface Strength: Application of Different Tests, Approaches and Parameters. Composites Science and Technology, 65, 149-160. http://dx.doi.org/10.1016/j.compscitech.2004.07.003

[30] Gotbatkina, Y.A., Ivanova-Mumjieva, V.G. and Goreberg, A.Y. (1999) Adhesive Strength of Bonds of Polymers with Carbon Fibers at Different Loading Rate. Fibre Chemistry, 31, 405-409. http://dx.doi.org/10.1007/BF02364376

[31] Gorbatkina, Y.A. and Ivanova-Mumjieva, V.G. (2009) Adhesion of Polymers to Fiber: Further Elaboration of Pull-Out Method. Polymer Science, 2, 214-216. 